\title{
Consequences for fetus and neonate of maternal red cell allo-immunisation
}

Helen Howard, Vanessa Martlew, Iain McFadyen, Cyril Clarke, Jennifer Duguid, Imelda Bromilow, John Eggington

\begin{abstract}
Aims-To study the distribution of clinically important red cell antibodies in pregnancy, and the associated fetal and neonatal morbidity and mortality.

Methods-The case notes of women with clinically important red cell antibodies identified in their serum during pregnancy were reviewed.

Results-During a 12 month period 22264 women were referred for antenatal screening. Clinically important red cell antibodies were detected in $244(1 \%)$. Of these, 100 were anti-D and 144 were non-RhD antibodies. There were three intrauterine deaths, three fetuses required intrauterine transfusion, 10 neonates were transfused, 27 others had phototherapy, and 27 with a positive direct antiglobulin test received no treatment. Early fetal losses occurred in the presence of both high and low levels of anti-D.

Conclusions-Anti-D remains the most common clinically important antibody in pregnancy, and accounts for the greatest fetal and neonatal morbidity and mortality. Of the other antibodies detected, anti-c was associated with most neonatal morbidity. The production of many of the non-D antibodies detected could be avoided by the use of selected red cells when transfusing pre-menopausal women. (Arch Dis Child Fetal Neonatal Ed 1998;78:F62-F66)
\end{abstract}

Keywords: allo-immunisation; pregnancy; red cell antibodies; haemolytic disease of the newborn

National Blood

Service,

Mersey and North

Wales Centre,

Liverpool L7 8TW

H Howard

V Martlew

J Duguid

I Bromilow

J Eggington

Department of Obstetrics and Gynaecology,

The Women's Hospital,

Liverpool

I McFadyen

Department of Biological Sciences, University of Liverpool C Clarke

Correspondence to: Dr Helen Howard.

Accepted 7 July 1997 cell antibodies has declined significantly since prophylaxis was introduced. ${ }^{1}$

Most red cell antibodies are IgG and thus can cross the placenta and may cause HDN. Those most commonly associated with moderate to severe haemolytic disease include those of the Rh system (especially anti-c) and of the Kell system. Other red cell antibodies may occasionally cause severe haemolytic disease in the fetus and neonate.
Methods

All women from seven of the maternity units which used the antenatal testing facilities of the Mersey and North Wales Blood Centre in the 12 months between December 1993 and November 1994 were identified. The case notes of mothers with red cell antibodies reported as "may cause HDN" were reviewed along with those of their babies, to establish morbidity and mortality in the fetus and neonate.

During the study period all pregnant women had their serum tested for red cell antibodies using two techniques. An indirect antiglobulin test (IAT) was used as this detects clinically important IgG antibodies which may cross the placenta, and an additional test using enzyme modified red cells which facilitates early detection of low levels of antibodies, some of which may be clinically important. Enzyme modified red cell testing may, however, produce nonspecific positive reactions which are not specific for IgG antibodies.

Women were tested at booking and this was repeated in $\mathrm{RhD}$ negative women at 28-34 weeks of gestation. Women with clinically important antibodies were monitored more frequently during the course of their pregnancy, and hospitals were advised about the frequency of testing required, according to antibody levels and their rates of change. Anti-D and anti-c levels were quantified using an auto-analyser technique, using the modified Marsh method. ${ }^{2}$ Other antibodies were monitored by titration, reported as a titre score. ${ }^{3}$ If anti-D was present an attempt was made to find out if the woman had been given prophylactic anti-D Ig during her pregnancy. All cases where anti-D was detected were followed up, even when detected only by enzyme tests. Other antibodies identified by IAT were reported as "may cause HDN" for follow up in this study. When identified only by enzyme tests throughout pregnancy, red cell antibodies were not considered clinically important and were excluded.

The obstetric history and a history of previous maternal blood transfusion were ascertained from request forms and review of the case notes.

\section{Results}

During the period of study, the serum samples from of 22264 pregnant women from the seven hospitals participating in the study were tested for antibodies associated with HDN. Expected dates of delivery ranged from 27 December 1993 to 1 July 1995. Potentially clinically 
Table 1 anti-D in pregnant women detected during study period

\begin{tabular}{|c|c|}
\hline anti-D IU/ml & Number (other antibodies) \\
\hline$>15$ & $\begin{array}{l}16(\mathrm{D}+\mathrm{C} 13 ; \mathrm{D}+\mathrm{C}+\mathrm{E} 3 ; \mathrm{D}+\mathrm{C}+\mathrm{S} 1 ; \\
\mathrm{D}+\mathrm{C}+\text { Kell } 1)\end{array}$ \\
\hline $4-15$ & $7(\mathrm{D}+\mathrm{C} 3)$ \\
\hline $1-4$ & $5(\mathrm{D}+\mathrm{C} 2 ; \mathrm{D}+\mathrm{E} 1)$ \\
\hline $0.25-1$ & $11(\mathrm{D}+\mathrm{C} 2)$ \\
\hline$<0.25$ IAT & $11(\mathrm{D}+\mathrm{C} 1)$ \\
\hline$<0.25$ enzyme only & $50(\mathrm{D}+\mathrm{E} 2)$ \\
\hline Associated with antenatal prophylactic anti-D Ig & 243 \\
\hline Total & 343 \\
\hline $\begin{array}{l}\text { Total NOT associated with antenatal } \\
\text { prophylactic anti-D IgG }\end{array}$ & $\begin{array}{l}100(\mathrm{D}+\mathrm{C} 21 ; \mathrm{D}+\mathrm{C}+\mathrm{E} 3 ; \mathrm{D}+\mathrm{C}+\mathrm{S} 1 ; \\
\mathrm{D}+\mathrm{C}+\text { Kell } 1 ; \mathrm{D}+\mathrm{E} 3)\end{array}$ \\
\hline
\end{tabular}

Table 2 Non-D clinically important antibodies (CSAs)

\begin{tabular}{lrl}
\hline & Total & $\begin{array}{l}\text { Transfusion } \\
\text { history }\end{array}$ \\
\hline Rhesus CSAs other than anti-D: & & \\
$\quad$ c, ce & 28 & 4 \\
C, Cw, Ce & 15 & 2 \\
E & 29 & 5 \\
e & 1 & \\
Total & 73 & 11 \\
Non-rhesus CSAs: & & \\
Kell & 42 & 28 \\
Jka & 10 & \\
Fya & 9 & 6 \\
S & 10 & 3 \\
$\quad$ Total & 71 & 37 \\
Total non-D CSAs & 144 & 48 \\
\hline
\end{tabular}

important red cell antibodies were initially identified in 487 (2\%) pregnancies, but 243 of the 343 women with anti-D had been treated with anti-D Ig during the pregnancy and were excluded from further follow up. Thus 244 (1\%) pregnancies with clinically important antibodies were reviewed (tables 1 and 2).

The outcomes of these pregnancies are summarised in tables 3 and 4 . Four women had two pregnancies during the study period (two with anti-D, one with anti-E, one with anti-S), of whom three lost their babies before 15 weeks of gestation (two in one woman with high levels of anti-D). There were a further six fetal losses before 15 weeks of gestation and one stillbirth not related to HDN.

ANTI-D

Immune anti-D was detected in 100 pregnancies (by IAT in 50 cases and by enzyme only in the remainder). Maximum levels and presence of other associated antibodies are shown in table 1. Fetal and neonatal morbidity and mortality in relation to anti-D levels are shown in table 3.

In the 50 cases where the anti-D levels was $<0.25 \mathrm{IU} / \mathrm{ml}$ and detected only by enzyme testing, the direct antiglobulin test (DAT) was negative in 43 babies (17 RhD positive) and positive in seven ( $5 \mathrm{RhD}$ positive). Of these seven, three $\mathrm{RhD}$ positive babies received phototherapy, but in one this was given only prophylactically based on a weakly positive DAT. In another baby the haemoglobin concentration was below $120 \mathrm{~g} / 1$ at birth with the serum bilirubin (SBR) rising to $240 \mu \mathrm{mol} / 1$ on the fourth day. The third baby had a maximum SBR of $214 \mu \mathrm{mol} / 1$ at day 5, with a fall in haemoglobin to just above $120 \mathrm{~g} / \mathrm{l}$ at 6 weeks of age. In these five RhD positive babies, as well as the two $\mathrm{RhD}$ negative babies with a positive DAT, there was also maternal ABO incompatibility.

The 11 mothers with anti-D levels $<0.25$ $\mathrm{IU} / \mathrm{ml}$ identified by IAT resulted in six babies with negative DAT (5 RhD positive), one stillbirth due to cardiac abnormality, and one miscarriage. Of the three remaining babies in this group, one with a positive DAT may have been due to ABO incompatibility (anti-D had

Table 3 anti-D level related to outcome of pregnancy

\begin{tabular}{|c|c|c|c|c|c|c|c|}
\hline Grade of HDN & $\begin{array}{l}<0.25 \mathrm{IU} / \mathrm{ml} \\
\text { enzyme only }\end{array}$ & $\begin{array}{l}<0.25 \mathrm{IU} / \mathrm{ml} \mathrm{IAT} \\
\text { (and enzyme) }\end{array}$ & $\begin{array}{l}0.25-1 \\
I U / m l\end{array}$ & $\begin{array}{l}1-4 \\
I U / m l\end{array}$ & $\begin{array}{l}4-15 \\
I U / m l\end{array}$ & $\begin{array}{l}>15 \\
I U / m l\end{array}$ & $\begin{array}{l}\text { Total (RhD } \\
\text { negative baby) }\end{array}$ \\
\hline DAT negative & 43 & $\star \star 7$ & 3 & 1 & 3 & 3 & $60(38)$ \\
\hline DAT positive but no treatment & $\star_{4}$ & 2 & 4 & 2 & 1 & & $13(3)$ \\
\hline Phototherapy & $\star 2$ & & 3 & 1 & & 2 & 8 \\
\hline $\mathrm{Hb}<120 \mathrm{~g} / 1$ no $\mathrm{Tx}$ & $\star 1$ & 1 & & & 2 & & 4 \\
\hline Exchange/top up $\mathrm{Tx}$ & & & & 1 & 1 & 4 & 6 \\
\hline IUT/LB & & & & & & 3 & 3 \\
\hline IUT/IUD & & & & & & 1 & 1 \\
\hline IUD $15-24$ weeks gestation & & & & & & 1 & 1 \\
\hline Fetal loss $<15$ weeks & & 1 & 1 & & & 2 & 4 \\
\hline Total & 50 & 11 & 11 & 5 & 7 & 16 & $100(41)$ \\
\hline
\end{tabular}

* In 7 babies from mothers with anti-D levels $<0.25 \mathrm{IU} / \mathrm{ml}$, detected only by enzyme testing, the positive DAT may have been due to ABO incompatibility.

$\star \star$ Includes one stillbirth due to cardiac abnormality.

NB: Babies with a negative DAT from mothers with anti-D levels $>0.25 \mathrm{IU} / \mathrm{ml}$, were also RhD negative.

DAT = direct antiglobulin test; IAT = indirect antiglobulin test; enz = enzyme tests; Hb = haemoglobin; $\mathrm{Tx}=$ exchange or top-up transfusion; IUT = intrauterine transfusion; IUD = intrauterine death; LB = live birth.

Table 4 Outcome of pregnancy related to antibody (antibodies other than anti-D)

\begin{tabular}{|c|c|c|c|c|c|c|c|c|c|}
\hline Grade of $H D N$ & $c, c e$ & $C, C w, C e$ & $E$ & $e$ & Kell & $\mathcal{F k a}$ & Fya & $S$ & Total (\%) \\
\hline DAT negative & 19 & 12 & 22 & & 34 & 6 & 5 & 6 & $104(72.2)$ \\
\hline DAT positive but no treatment & 2 & $\star_{2}$ & 3 & & 2 & 1 & 2 & 2 & $14(9.7)$ \\
\hline Phototherapy & 2 & 1 & 3 & 1 & 2 & $\star 3$ & 1 & & $13(9.0)$ \\
\hline $\mathrm{Hb}<120 / \mathrm{gl}$ no $\mathrm{Tx}$ & 1 & & & & & & & 1 & $2(1.4)$ \\
\hline Exchange/top up $\mathrm{Tx}$ & 3 & & 1 & & & & & & $4(2.8)$ \\
\hline IUT & & & & & & & & & 0 \\
\hline Fetal loss $>15$ weeks & & & & & 1 & & & & $1(0.7)$ \\
\hline Fetal loss $<15$ weeks & 1 & & & & 3 & & 1 & 1 & $6(4.2)$ \\
\hline Total & 28 & 15 & 29 & 1 & 42 & 10 & 9 & 10 & $144(100)$ \\
\hline
\end{tabular}

$\star 2$ may have been due to ABO incompatibility ( 1 anti-Cw, 1 anti-Jka).

DAT = direct antiglobulin test; IAT = indirect antiglobulin test; enz = enzyme tests; $\mathrm{Hb}=$ haemoglobin; $\mathrm{Tx}=$ transfusion; IUT = intrauterine transfusion; IUD = intrauterine death; LB = live birth. 
disappeared by the end of the pregnancy); and of the other two, one woman had premature twins given phototherapy (haemoglobin $<120$ $\mathrm{g} / \mathrm{l}$ at 8 weeks, consistent with low birthweight), and the other baby required no treatment.

All 10 of the 39 with levels $>0.25 \mathrm{IU} / \mathrm{ml}$, where the DAT in the baby was negative, were $\mathrm{RhD}$ negative babies. In seven with a positive DAT, no treatment was given (for maximum SBRs ranging form $69-142 \mu \mathrm{mol} / \mathrm{l})$. One woman with anti-D levels $>20 \mathrm{IU} / \mathrm{ml}$ and associated with anti-C, lost the baby at 10 and 14 weeks of gestation, respectively, in two pregnancies registered during the period of study. Another woman's baby died in utero at 18 weeks of gestation and her anti-D levels were $655 \mathrm{IU} / \mathrm{ml}$ at that time. The remaining intrauterine death occurred at 20 weeks, a few days after an intrauterine transfusion, in a woman with levels up to $188 \mathrm{IU} / \mathrm{ml}$, while the three other pregnancies which required between three and five intrauterine transfusions for each case, resulted in live births. In all these seven severely affected pregnancies the maternal serum also contained anti-C (including one with anti-E, one with anti-S, and one with antiKell).

Six neonates required exchange or top up transfusions. A further four babies with haemoglobin concentrations of $<120 \mathrm{~g} / 1$ were treated with phototherapy but were not transfused (including two referred to above where the mothers' anti-D levels were $<0.25 \mathrm{IU} / \mathrm{ml}$ ). Four babies with low haemoglobin values with or without transfusion, were born to mothers with anti-D+C. Six other babies had phototherapy for maximum SBRs, ranging form 140-399 $\mu \mathrm{mol} / 1$, and of these, four mothers had anti-D+C and one also had anti-E.

ANTIBODIES OTHER THAN ANTI-D

Antibodies other than anti-D were reported as "may cause HDN" in 144 pregnancies (140 were detected by IAT and four with anti-c detected only by enzyme tests). Of these, 73 were other antibodies in the Rh system and 71 were non-Rh antibodies (table 2). In 11/73 $(15 \%)$ of those with $\mathrm{Rh}$ antibodies there was a history of previous blood transfusion, as there was in $37 / 71(52 \%)$ of those with non-Rh antibodies.

Pregnancy outcome is summarised in table 4. One woman, with an anti-Kell level score of 35 and a history of transfusion, had a fetal loss at 19 weeks of gestation. Four other women with anti-Kell had babies with a positive DAT, but no significant jaundice or anaemia, although two were given prophylactic phototherapy.

Of the three women with anti-c whose babies required exchange or top up transfusions, two had maximum anti-c levels of $24.5 \mathrm{IU} / \mathrm{ml}$ (none in previous pregnancy) and $29.5 \mathrm{IU} / \mathrm{ml}$, and the minimum haemoglobin concentrations in the babies were $81 \mathrm{~g} / 1$ and $96 \mathrm{~g} / \mathrm{l}$, respectively. In the third woman anti-c was not detected during pregnancy, but only after delivery because of jaundice in the baby, whose minimum haemoglobin was $74 \mathrm{~g} / 1$ and maximum SBR $432 \mu \mathrm{mol} / 1$. At subsequent testing of the mother five months later her anti-c level was $83.5 \mathrm{IU} / \mathrm{ml}$. A woman with anti-c+E (anti-c level $8.2 \mathrm{IU} / \mathrm{ml}$, maximum anti-E level score of 30) and a history of previous pregnancies resulting in severe HDN, had a baby with minimum haemoglobin of $85 \mathrm{~g} / 1$ and a maximum SBR $339 \mu \mathrm{mol} / \mathrm{l}$; the baby was not transfused, but was treated with phototherapy. Four other women with anti-c had babies with a positive DAT (including one case where anti-c had only been detected by enzyme tests), of whom two were given phototherapy.

One woman with an anti-E level score of 52, had a baby whose minimum haemoglobin was $65 \mathrm{~g} / 1$ and maximum SBR $325 \mu \mathrm{mol} / 1$, requiring two exchange and one top up transfusions. She had no transfusion history. Her partner was $\mathrm{cDE} / \mathrm{cDE}$ and she had conceived one previous pregnancy with him which had been therapeutically terminated. Six other women with anti-E had babies with a positive DAT, but no clinically important jaundice or anaemia, although three were given phototherapy.

One woman with a maximum anti-S level score of 48 , had a baby with a strongly positive DAT. The initial haemoglobin at delivery was $180 \mathrm{~g} / 1$, which fell to $116 \mathrm{~g} / 1$ at 1 month of age.

A woman with an anti-Fy ${ }^{\mathrm{a}}$ maximum level score of 34, had a history of transfusion after her last pregnancy. Her baby had positive DAT ( Fy type not determined) and was given phototherapy for an SBR rising to $339 \mu \mathrm{mol} / 1$.

Other babies with a positive DAT who were given phototherapy all had haemoglobin values within normal limits and only moderate jaundice, as had those babies with a positive DAT and not given phototherapy.

Of the 244 cases with clinically important antibodies, nine babies (3\%) had a positive DAT which may have been associated with ABO incompatibility.

\section{Discussion}

This study shows that anti-D remains the principal red cell antibody resulting in morbidity and mortality due to HDN, ${ }^{1}$ despite the use of prophylactic anti-D Ig. Non-D Rh antibodies exceed antibodies from other systems and antiKell accounts for $60 \%$ of the remainder.

In two thirds of pregnancies where anti-D was detected, it followed administration of anti-D Ig during pregnancy. Passive anti-D can be detected by enzyme tests and IAT for 12 weeks or more after anti-D Ig, and it cannot be differentiated from immune anti-D. ${ }^{4}$

New guidelines for red cell antibody testing during pregnancy were published in 1996, recommending that all pregnant women should be tested for clinically important red cell antibodies at booking and if none is detected, they should be retested during 28-36 weeks of gestation. In this study a primigravida with no anti-D detected at 28 weeks subsequently developed anti-D of $>150 \mathrm{IU} / \mathrm{ml}$ after an episode of abdominal pain at 30 weeks of gestation, with the baby having a positive DAT and requiring phototherapy. Increasing the frequency of routine testing would have cost implications, although this may be partially 
offset by rationalising screening to exclude enzyme testing, as it is thought that antibodies not detected by IAT are unlikely to be of any importance. ${ }^{5}$

In this study there were 50 women with anti-D levels $<0.25 \mathrm{IU} / \mathrm{ml}$ detected only by enzyme tests throughout pregnancy. Seven of these babies had a positive DAT which could have been due to ABO incompatibility. One woman with anti-c detected only by enzyme testing had a baby with a positive DAT, but no treatment was required. Table 3 confirms the relation between anti-D level and severity of HDN. Those cases requiring intrauterine transfusion or where the baby died in utero all had levels $>15 \mathrm{IU} / \mathrm{ml}$, and most of the women whose babies had a low haemoglobin with or without transfusion being undertaken, had levels $>4 \mathrm{IU} / \mathrm{ml}$. This is in line with previous findings. ${ }^{46}$ Fetal mortality from fetal blood sampling is $<1 \%$, and the risk from direct intravascular fetal transfusion is $0.8 \%$ per procedure (compared with $3.5 \%$ for intraperitoneal fetal transfusion). ${ }^{7}$ Thus measurement of the maternal anti-D level has a role in determining when such interventions should be considered. In this study there was one intrauterine death at 20 weeks of gestation after an intrauterine transfusion two days earlier. At the other end of the spectrum there was little morbidity at levels $<0.25 \mathrm{IU} / \mathrm{ml}$, although there were four babies given phototherapy, of whom two had haemoglobin values below $120 \mathrm{~g} / 1$. In all mothers with levels $>0.25 \mathrm{IU} / \mathrm{ml}$ who gave birth to $\mathrm{RhD}$ positive babies, the baby also had positive DAT. There was less correlation between anti-D levels and outcome earlier in pregnancy, as fetal loss before 15 weeks of gestation occurred in mothers with both high and low levels of anti-D

The presence of anti-C in association with anti-D may be of considerable clinical importance. Anti-C was found in association with anti-D, in both cases resulting in intrauterine death and in all cases requiring intrauterine transfusion. Half the cases where the baby required exchange or top up transfusion also had anti-C. In those with anti-C some had other antibodies such as anti-E or anti-S. No serious fetal or neonatal mortality or morbidity occurred where there was maternal anti-C in the absence of anti-D. The presence of anti-D+C also suggests the presence of anti-G, which would normally go undetected and could result in HDN. ${ }^{8}$

Anti-c and antibodies of the Kell system are those most likely to cause severe HDN, with anti-Fy ${ }^{\mathrm{a}}$, anti-C, and anti-E as less common causes. Other antibodies may rarely cause clinically relevant $\mathrm{HDN} .^{4}{ }^{7}$ With antibodies other than anti-D, the severity of HDN is related to the concentration of the antibody, except for Kell related antibodies. ${ }^{4}{ }^{9}$ The presence of anti-Kell in maternal plasma may be associated with severe anaemia in the fetus and sometimes the intrauterine death of a hydropic fetus. Anti-Kell is associated with an inhibitory effect on fetal erythropoiesis, which is independent of antibody concentration. Fetal monitoring is therefore best undertaken by serial ultrasound examination to detect early evidence of fetal oedema.

Among the non-D antibodies anti-c was the cause of greatest neonatal morbidity in this study, with four babies having haemoglobin values $<120 \mathrm{~g} / 1$, of whom three required transfusion. The case with anti-E on its own, where the baby required an exchange and top up transfusions, is unusual. Other cases with anti-E where there was significant HDN also had other antibodies (one with anti-D and one with anti-C). In this study there was also one case with anti-S where the baby had a haemoglobin concentration of $<120 \mathrm{~g} / 1$, and one case with anti-D+C requiring intrauterine transfusion also had anti-S. Anti-Fy level scores up to 34 in one case resulted in a baby with very a high SBR.

The commonest cause of feto-maternal blood group incompatibility is anti-A or anti-B in group $\mathrm{O}$ mothers with group $\mathrm{A}$ or $\mathrm{B}$ babies. However, this rarely results in severe HDN requiring exchange transfusion. In this study a positive DAT in nine babies may have been associated with mild $\mathrm{ABO}$ incompatibility, but none required exchange transfusion.

Many women with antibodies other than anti-D gave a history of blood transfusion. In $15 \%$ of those with non-D Rh antibodies and in $52 \%$ of those with non-Rh antibodies the selection of red cells might have prevented immunisation. In recent years automation of blood grouping has facilitated the provision of phenotyped red cells, and consideration should be given to the recommendation of routine prescription of Kell negative blood to premenopausal women (in the absence of cellano antibody).

This study confirms that anti-D remains the most common cause of serious morbidity and mortality in the fetus and neonate. Many cases in this study had already had one or more severely affected pregnancies. It is therefore vital to ensure that current recommendations for the use of anti-D Ig after delivery, and for events during pregnancy associated with fetomaternal haemorrhage, are adequately understood and followed up. ${ }^{10}$ Studies on its use have shown current practice to fall short of these recommendations during pregnancy by up to $40 \% .{ }^{11}{ }^{12}$ This is especially so in early pregnancy, but later on there can be confusion about the role of tests such as the Kleihauer to estimate the volume of feto-maternal haemorrhage, and the need to administer anti-D Ig after abdominal trauma is often not recognised. ${ }^{12}$ The policy for prevention was reviewed at a consensus conference on anti-D prophylaxis in April 1997. ${ }^{13}$ The importance of adherence to guidelines for the use of anti-D Ig was emphasised in the consensus statement. Failures of compliance are particularly common after potentially sensitising events during pregnancy, both in relation to administration of anti-D Ig and tests to estimate the size of fetomaternal haemorrhage, such as the Kleihauer test. It was also emphasised that there should be awareness of the need for anti-D Ig not only in obstetric and midwifery units but also among primary care staff and in accident and 
emergency departments. An expert group within the British Blood Transfusion Society and the Royal College of Obstetricians and Gynaecologists is currently reviewing the 1991 recommendations, and new guidelines will be published shortly. The Consensus Panel ${ }^{13}$ also concluded that women become sensitised by small feto-maternal haemoglobins which are undetected. These are most likely to occur in the last 12 weeks of pregnancy, and it was proposed that antenatal prophylaxis with anti-D Ig should be introduced routinely in the third trimester. However, the use of anti-D Ig has significantly reduced morbidity and mortality due to anti-D, ${ }^{1}$ so that its prevalence in relation to other red cell antibodies has declined and they have become increasingly implicated as a cause of HDN. ${ }^{14}{ }^{14}{ }^{15}$ It is therefore important that red cell antibody testing during pregnancy should be adequately performed in accordance with current guidelines, ${ }^{4}$ so that pregnancies at risk of fetal and neonatal HDN can be identified, and those likely to need treatment during the fetal or neonatal period can be predicted at the earliest opportunity. Laboratories undertaking such antenatal testing should have an effective working relationship with obstetricians and paediatricians so that there is optimal antenatal and perinatal care.

We thank the staff of the seven maternity units involved, for all their help in supplying case notes for the study.

1 Clarke CA, Hussey RM. Decline in deaths from Rhesus of the new-born. $7 \mathrm{R}$ Coll Physicians Lond 1994;28:310-11.
2 Marsh WL, Nichols M, Jenkins WJ. Automated detection of blood group antibodies. F Med Lab Technol 1968;25:33542.

3 American Association of Blood Banks. Method 4.3 Antibody titration. In: Walker R H, ed. Technical Manual. 10th edn. Chicago: AABB Press, 1990: 567-9.

4 British Committee for Standards in Haematology. Blood Transfusion Task Force. Guidelines for blood grouping and red cell antibody testing during pregnancy. Transfusion Med 1996;6:71-4.

5 Issitt PD, Combs MR, Bredehoeft SJ, et al. Lack of significance of "enzyme-only" red cell alloantibodies. Transfusion 1993:33:284-93.

6 Nicolaides $\mathrm{KH}$, Rodeck CH, Maternal serum anti-D antibody concentration and assessment of rhesus isoimmunisation. BMF 1992;304:1155-6.

7 Bowman JM. Hemolytic disease of the new-born. Vox Sang 1996;70(suppl 3):62-7.

8 Hadley AG, Poole GD, Poole J, Anderson NA, Robson M. Haemolytic disease of the newborn due to anti-G. Vox Sang 1996;71:108-12.

9 Vaughan JI, Warwick R, Letsky EA, Nicolini U, Rodeck CH, Fisk NM. Erythropoiesis suppression in foetal anaemia because of Kell alloimmunisation. 7 Obstet Gynecol 1994;171:247-52.

10 NBTS Immunoglobulin Working Party. Recommendations for the use of anti-D immunoglobulin. Prescribers fournal 1991;31:137-45.

11 Hughes RG, Craig JIO, Murphy WG, Greer IA. Causes and clinical consequences of Rhesus (D) haemolytic disease of the new-born: a study of a Scottish population 1985-1990. the new-born: a study of a Scottish populat
Br f Obstet Gynaecol 1994;101:297-300.

12 Howard HL, Martlew VJ, McFadyen IR, Clarke CA. Preventing Rhesus(D) haemolytic disease of the new-born by giving anti-D immunoglobulin: are the guidelines being adequately followed? Br f Obstet Gynaecol 1997;104:34-41.

13 Consensus Statement. Royal College of Physicians of Edinburgh/Royal College of Obstetricians and Gynaecologists Consensus Conference on anti-D Prophylaxis 7, 8 April 1997. Transfusion Med 1997;7:143-4.

14 Geifman-Holtzman O, Wojtowycz M, Kosmas E, Artal R. Female alloimmunization with antibodies known to cause hemolytic disease. Obstet Gynecol 1997;89:272-5.

15 Filby D, Hanson U, Wesstrom G. The prevalence of red cell antibodies in pregnancy correlated to the outcome of the newborn: a 12 year study in central Sweden. Acta Obstet Gynecol Scand 1995;74:687-92. 